\title{
The Feasibility of Activation of Manganese Minerals Flotation
}

\author{
By A. M. Abeidu*
}

\begin{abstract}
The feasibility and the mechanism of activation of pyrolusite, manganite, and rhodochrosite with $\mathrm{Fe}$ (III), $\mathrm{Cu}$ (II) and Mn (II) in an anionic collector system using oleic acid as the collector have been investigated. The results obtained showed a certain regularity as basically determined by the acidity of the heavy metal cation and the $\mathrm{pH}$ of its precipitation, the $p K_{a}$ of the oleic acid, the chemical composition of the manganese mineral tested, and the $\mathrm{pH}$ of its isoelectric point. Thus, $\mathrm{Cu}$ (II) and $\mathrm{Mn}$ (II) which are basic and hydrolyze at $\mathrm{pHs}$ above those of the isoelectric points of the manganese minerals investigated could, within certain specific limits of medium $\mathrm{pH}$, act as activators for pyrolusite and manganite. On the other hand, $\mathrm{Fe}$ $\left(\mathrm{H}_{2} \mathrm{O}\right)_{6}^{+++}$which is acidic, ionizes at $\mathrm{pH} 2.2$ and is precipitated at $\mathrm{pH} 3.7$, which is below than both the isoelectric point of the manganese minerals studied and the $p K_{a}$ of oleic acid, is of no particular advantage in the activation and flotation. The response of rhodochrosite, without pre-activation, to soap flotation seems to be due to the basic property of the bivalent manganese sites in its crystalline lattice, which produces a tendency for the attachment of oleic acid. Owing to the negative surface charge of the manganese minerals at $\mathrm{pH}$ above 5 and the positive surface charge of the gangue minerals (barite, gypsum, calcite), the anion, $\mathrm{Al}_{2} \mathrm{SiO}_{3}(\mathrm{OH})_{6}^{--}$, resulting from the conjunction of $\mathrm{Na}_{2} \mathrm{SiO}_{3}$ with $\mathrm{Al}_{2}\left(\mathrm{SO}_{4}\right)_{3}$ is adsorbed preferentially to the surface of the latter leading to a successful differential flotation.
\end{abstract}

(Received May 11, 1972)

\section{Introduction}

Each type of a manganese deposit is a problem by itself in the matter of selection of a proper method of concentration, depending on the manganese minerals and their gangue constituents. In the Elba region of the Eastern Desert of Egypt occurs a manganese deposit in which the manganese minerals are represented by pyrolusite $\left(\mathrm{MnO}_{2}\right)$ and manganite $(\mathrm{MnO}$ $(\mathrm{OH}))$. Rhodochrosite $\left(\mathrm{MnCO}_{3}\right)$ is rather rare. Of the gangue minerals, the removal of barite $\left(\mathrm{BaSO}_{4}\right)$, gypsum $\left(\mathrm{CaSO}_{4}\right)$ and calcite $\left(\mathrm{CaCO}_{3}\right)$ presents the greatest difficulty. In this paper the possibility and the mechanism of activation and selective flotation of the manganese minerals were investigated.

\section{Experimental Techniques}

The reagents were of the analytical grade. In view of the availability of reasonably pure natural crystals of pyrolusite, manganite, rhodochrosite, calcite, barite and gypsum from the Elba region in the Eastern Desert of Egypt, natural crystals of these minerals were used. The crystals were crushed in a porcelain mortar and screened to give $-100,+150$ mesh fraction for flotation tests and $-150,+200$ mesh fraction for streaming potential studies. The description of the Hallimond tube used is given in a previous paper ${ }^{(1)}$. The equipment used for the electrokinetic measurements was the same as that used earlier ${ }^{(2)}$. The procedure used for adsorption studies with oleic acid is with a high degree of accuracy $( \pm 10 \%)$ and also sensitivity $(0.02 \%)^{(3)(4)}$. It is based on the measurements of the optical density of $\mathrm{OlH}$ in the infrared region of the

* Laboratory of Metallurgy, National Research Centre, Egypt.

(1) A. M. Abeidu: J. Less-Common Metals, 22 (1970), 355.

(2) A. M. Abeidu: J. of Mines, Metals \& Fuels, 17 (1969), 80.

Trans. JIM spectrum with the frequency at $1720 \mathrm{~cm}^{-1}$. The procedure is described elsewhere ${ }^{(3)(4)}$.

\section{Results and Discussion}

The influence of $\mathrm{pH}$ on the surface electrokinetic properties of manganese and gangue minerals has been studied. The isoelectric point of pyrolusite, manganite and rhodochrosite was noticed at $\mathrm{pH} \mathrm{3.8,3.9} \mathrm{and} \mathrm{4.8,}$ respectively. It seems likely that $>\mathrm{MnOH}$ site predominates around the $\mathrm{pH}$ of the iseelectric point, whereas $>\mathrm{MnOH}_{2}^{+}$and $>\mathrm{MnO}^{-}$predominates below and above it, respectively. There was no change in the sign of the electrical charge of barite, calcite and gypsum in the $\mathrm{pH}$ range from 1.5 to 11 which means that the isoelectric points were not reached, although the value of the zeta potential decreased at high and low $\mathrm{pH}$ values, due presumably to the compression of the electrical double layer.

It is to be noted that the effect of metal cations on the zeta potential of a manganese mineral differs from one cation to another. Thus $\mathrm{Fe}$ (III) has no effect on the zeta potential of pyrolusite and manganite at $\mathrm{pH}$ above 2.5 and a mild effect on their zeta potential at pH below 2.5. By contrast, $\mathrm{Cu}$ (II) and $\mathrm{Mn}$ (II) affect markedly the zeta potential of manganese minerals over a wide $\mathrm{pH}$ range $(3 \sim 9)$. The form of the curves for the zeta potential of manganese minerals in the presence of $\mathrm{Cu}$ (II) profoundly differs from those in the presence of $\mathrm{Mn}$ (II). Study of these curves reveals a certain regularity for the influence of each cation on the zeta potential. As seen from Figs. $1 \sim 3 \mathrm{Cu}$ (II) has a maximum effect at $\mathrm{pH}$ of about 7 on the zeta potential, whereas $\mathrm{Mn}$ (II) has two maxima of effects, which were noticed at $\mathrm{pH}$ of about 5 and 8.5. Before

(3) A. M. Abeidu: Indian J. of technology, 9 (1971), 344.

(4) A. Ya. Zhavoronkova, E. I. Moiseeva, S. A. Shelkova and N. F. Mishin: The Soviet J. of non-ferr. Metals, 8 (4) (1967), 28.

1973 Vol. 14 


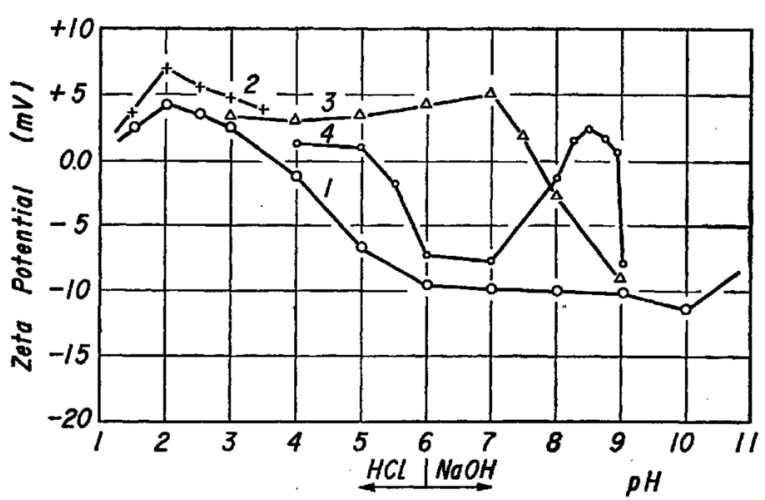

Fig. 1 Zeta potential of pyrolusite as a function of $\mathrm{pH}$ : (1) without any additions; (2) in the presence of $50 \mathrm{mg} / \mathrm{L}$ of $\mathrm{FeCl}_{3} ;(3)$ in the presence of 50 $\mathrm{mg} / \mathrm{L} \mathrm{CuSO}{ }_{4} ;(4)$ in the presence of $50 \mathrm{mg} / \mathrm{L}$ $\mathrm{MnSO}_{4}$.

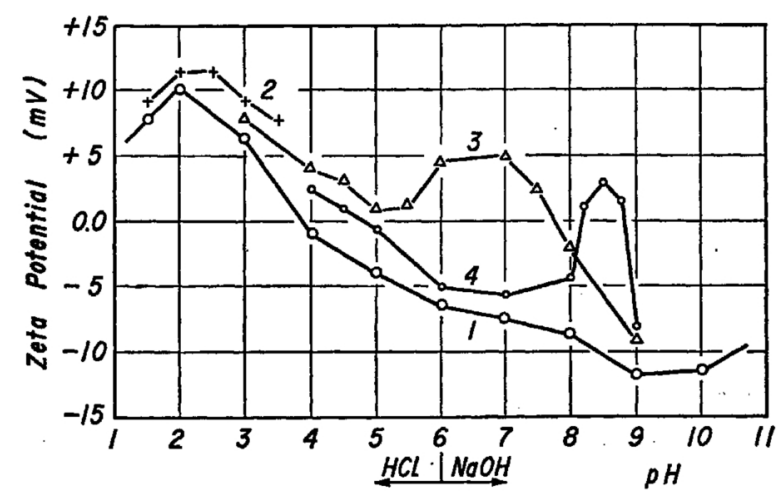

Fig. 2 Zeta potential of manganite as a function of $\mathrm{pH}$ : (1) without any additions; (2) in the presence of $50 \mathrm{mg} / \mathrm{L} \mathrm{FeCl}_{3} ;(3)$ in the presence of $50 \mathrm{mg} / \mathrm{L}$ of $\mathrm{CuSO}_{4} ;$ (4) in the presence of 50 $\mathrm{mg} / \mathrm{L}$ of $\mathrm{MnSO}_{4}$.

any interpretation of the data of Figs. $1 \sim 4$, it is necessary to consider the state of both the cations tested and the surface sites in the crystalline lattice of the manganese minerals over a range of $\mathrm{pH}$. $\mathrm{Fe}\left(\mathrm{H}_{2} \mathrm{O}\right)_{6}^{+++}$is a fairly strong acid ${ }^{(5)}$ and undergoes acid ionization ${ }^{(6)}$ such as:

$$
\begin{array}{r}
\mathrm{Fe}\left(\mathrm{H}_{2} \mathrm{O}\right)_{6}^{+++}=\mathrm{Fe}\left(\mathrm{H}_{2} \mathrm{O}\right)_{5} \mathrm{OH}^{++}+\mathrm{H}^{+} \\
(\mathrm{pH} 2.2) \\
\mathrm{Fe}\left(\mathrm{H}_{2} \mathrm{O}\right)_{5} \mathrm{OH}^{++}=\mathrm{Fe}\left(\mathrm{H}_{2} \mathrm{O}\right)_{4}(\mathrm{OH})_{2}^{+}+\mathrm{H}^{+} \\
(\mathrm{pH} \mathrm{3.2)} \\
\mathrm{Fe}\left(\mathrm{H}_{2} \mathrm{O}\right)_{4}(\mathrm{OH})_{2}^{+}=\mathrm{Fe}\left(\mathrm{H}_{2} \mathrm{O}\right)_{3}(\mathrm{OH})_{3}+\mathrm{H}^{+} \\
(\mathrm{pH} 3.7)
\end{array}
$$

The first ionization constant for $\mathrm{Fe}\left(\mathrm{H}_{2} \mathrm{O}\right)_{6}^{+++}$is comparable to the second ionization constant for sulfuric acid ${ }^{(5)}$, being about $10^{-2}$. On the other hand, $\mathrm{Cu}(\mathrm{II})$. is a weak base ${ }^{(5)}$ and ionizes as follows ${ }^{(7)}$ :

(5) R. B. Fischer and D. G. Petters: Basic theory and practice of quantitative chemical analysis, 3rd ed., W. B. Saunders Company, Philadelphia, London, Toronto, (1968), p. 380, 588.

(6) L. Pauling: General chemistry, 2nd ed., W. H. Freeman and Co., San Francisco, (1956), p. 446.

(7) T. Moeller: Inorganic chemistry, John Wiley and Sons, New York, (1952), p. 502.

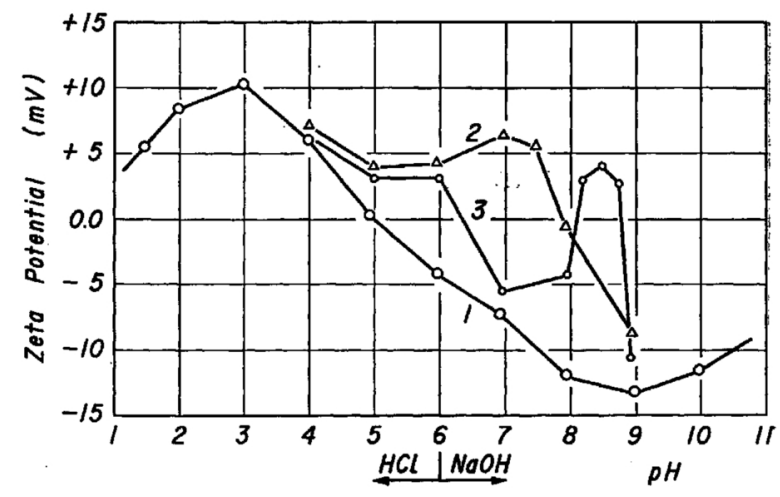

Fig. 3 Zeta potential of a rhodochrosite as a function of $\mathrm{pH}$ : (1) without any additions; (2) in the presence of $50 \mathrm{mg} / \mathrm{L}$ of $\mathrm{CuSO}_{4}$; (3) in the presence of $50 \mathrm{mg} / \mathrm{L}$ of $\mathrm{MnSO}_{4}$.

N.B.: $\mathrm{FeCl}_{3}$ is almost without effect on the zeta potential.

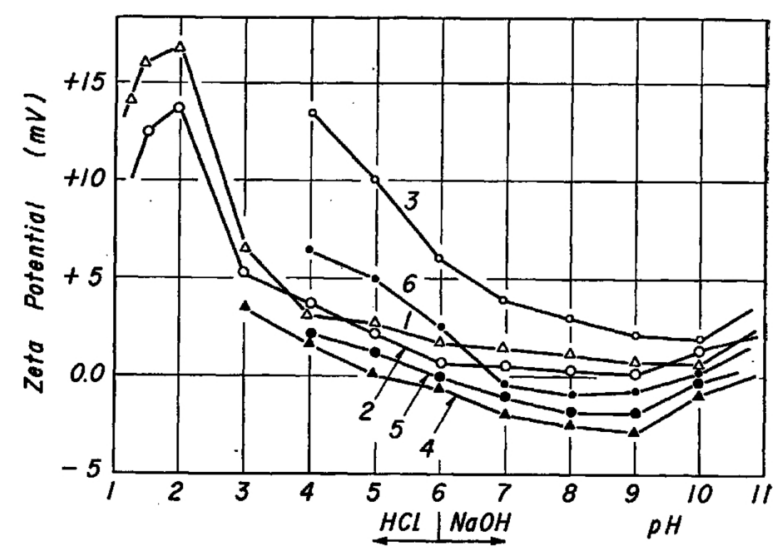

Fig. 4 Zeta potential of minerals as a function of $\mathrm{pH}$ without any additions: (1) barite; (2) gypsum; (3) calcite.

Zeta potential of minerals as a function of $\mathrm{pH}$ in the presence of the reagent mixture (50 $\left.\mathrm{mg} / \mathrm{L} \quad \mathrm{Na}_{2} \mathrm{SiO}_{3}+50 \mathrm{mg} / \mathrm{L} \quad \mathrm{Al}_{2}\left(\mathrm{SO}_{4}\right)_{3}\right):$ (4) barite; (5) gypsum; (6) calcite.

$$
\begin{array}{r}
\mathrm{Cu}\left(\mathrm{H}_{2} \mathrm{O}\right)_{4}^{++}=\mathrm{Cu}\left(\mathrm{H}_{2} \mathrm{O}\right)_{3} \mathrm{OH}^{+}+\mathrm{H}^{+} \\
(\mathrm{pH} 5.3) \\
\mathrm{Cu}\left(\mathrm{H}_{2} \mathrm{O}\right)_{3} \mathrm{OH}^{+}=\mathrm{Cu}\left(\mathrm{H}_{2} \mathrm{O}\right)_{2}(\mathrm{OH})_{2}+\mathrm{H}^{+} \\
(\mathrm{pH} 8)
\end{array}
$$

Similarly for $\mathrm{Mn}(\mathrm{II})$ :

$$
\begin{aligned}
& \mathrm{Mn}^{++}+\mathrm{H}_{2} \mathrm{O}=\mathrm{Mn}(\mathrm{OH})^{+}+\mathrm{H}^{+} \\
& \text {(pH 7.9) } \\
& \mathrm{Mn}(\mathrm{OH})^{+}+\mathrm{H}_{2} \mathrm{O}=\mathrm{Mn}(\mathrm{OH})_{2}+\mathrm{H}^{+} \\
& \text {(pH 8.9) }
\end{aligned}
$$

Of the ionic species, $\mathrm{Mn}^{++}, \mathrm{Mn}(\mathrm{OH})^{+}, \mathrm{Cu}(\mathrm{OH})^{+}$and to some extent $\mathrm{Cu}^{++}$show a concentration of $\mathrm{pH}$ relationship similar to the zeta potential. Iron ionic species, $\mathrm{Fe}^{+++}$, and especially its hydroxide complex, $\mathrm{Fe}(\mathrm{OH})^{++}$and $\mathrm{Fe}(\mathrm{OH})_{2}^{+}$, do not show such a relationship. Consequently, the mechanism of activation of the manganese minerals by metal cations tested seems to be as follows:

$>\mathrm{MnO}^{-}+\mathrm{MnOH}^{+}=>\mathrm{MnO} \ldots$.HOMn

(pH $8 \sim 9$ ) 


$$
\begin{aligned}
& >\mathrm{MnOH}+\mathrm{Mn}^{++}=>\mathrm{MnOH} . . \mathrm{Mn}^{++} \\
& \text {(pH } 3 \sim 5)
\end{aligned}
$$

Similarly for $\mathrm{Cu}(\mathrm{II})$

$$
\begin{aligned}
>\mathrm{MnO}^{-}+\mathrm{CuOH}^{+}= & \underset{ }{\mathrm{MnO}} \ldots \mathrm{HOCu} \\
& (\mathrm{pH} 5 \sim 8) \\
>\mathrm{MnOH}+\mathrm{Cu}^{++}= & \underset{\mathrm{MnOH}}{\mathrm{MH}} \sim \mathrm{Cu}^{++}
\end{aligned}
$$

The symbol $>$ represents schematically the lattice surface.

In the case of $\mathrm{Fe}$ (III)

The hydroxide complex, $\mathrm{Fe}(\mathrm{OH})^{++}$and $\mathrm{Fe}(\mathrm{OH})_{2}^{+}$ predominate in the $\mathrm{pH}$ range $2.2 \sim 3.7$ but the suitable manganese surface sites $>\mathrm{MnO}^{-}$for their attachment are not available in this $\mathrm{pH}$ range owing to the fall of the isoelectric point of the manganese minerals at $\mathrm{pHs}$ above 3.5. This may explain the small change in the value of the zeta potential caused by the addition of $\mathrm{Fe}$ (III).

The abrupt change in the zeta potential of barite and gypsum (Fig. 4 ) in the $\mathrm{pH}$ range $2 \sim 3$ coupled with the high degree of dissociation of $\mathrm{SO}_{4} \mathrm{H}^{-}$, which is about $10^{-2}$ are indications to the following configuration of sulphate sites:

$$
>\mathrm{SO}_{4} \mathrm{H}=>\mathrm{SO}_{4}^{-}+\mathrm{H}^{+} \quad(\mathrm{pH}>2)
$$

On the other hand, the merely reduction of the zeta potential without change in its sign in the $\mathrm{pH}$ range $3 \sim 5$ and the approaching of the zeta potential to the vanishing point in the $\mathrm{pH}$ range $6 \sim 10$ suggest that the surface sites $>\mathrm{BaOH}_{2}^{+}$and $>\mathrm{CaOH}_{2}^{+}$predominate at $\mathrm{pH}$ below 5 , whereas $>\mathrm{BaOH}$ and $>\mathrm{CaOH}$ predominate from $\mathrm{pH} 6$ to $\mathrm{pH} 10$. It is to be noted that the zeta potential of the gangue minerals is insensitive to the metal cations tested. It seems likely that the interfacial electrical conditions (Fig. 4) makes the attachment of the positively charged metal cation species (eqs. (1) $\sim(7)$ ) to the positively charged surfaces of the gangue minerals rather improbable. On the other hand, these surfaces could bond the anionic collector species as follows:

In the case of gypsum and calcite

$$
\begin{aligned}
& >\mathrm{CaOH}+\mathrm{Ol}^{-}=>\mathrm{CaOH} . \mathrm{Ol}^{-} \\
& \text {(pH } 6 \sim 10) \\
& >\mathrm{CaOH}_{2}^{+}+\mathrm{Ol}^{-}=>\mathrm{CaOH}_{2} \cdot \mathrm{Ol} \\
& \text { (pH 6) } \\
& >\mathrm{CaOH}+\mathrm{OlH}=>\mathrm{CaOH} . \mathrm{HO} \\
& \text { (pH } 6 \sim 8.5 \text { ) }
\end{aligned}
$$

In the case of barite a similar mechanism takes place but instead of the calcium sites there are barium sites. Thus, the surface sites of the calcite, the barite, and the gypsum are suitable for the attachment of the anionic collector (oleic acid) species (Fig. 5). Subsequently, they respond well to soap flotation (Fig. 6). In order to impede the co-flotation of these gangue minerals with the manganese minerals, the use of a selective and an effective depressant is indispensable.

Experimentation with the reagent mixture of water glass $\left(\mathrm{Na}_{2} \mathrm{SiO}_{3}\right)+$ aluminium sulphate $\left(\mathrm{Al}_{2}\left(\mathrm{SO}_{4}\right)_{3}\right)$

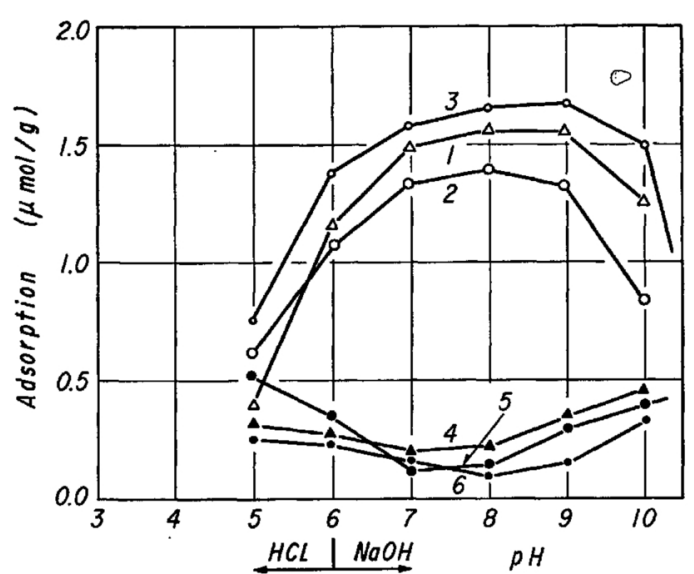

Fig. 5 The uptake of oleic acid from solution (100 $\mathrm{mg} / \mathrm{L}$ ) by: (1) barite; (2) gypsum; (3) calcite; Uptake in the presence of the reagent mixture $\left(50 \mathrm{mg} / \mathrm{L} \mathrm{Na} \mathrm{SiO}_{3}+50 \mathrm{mg} / \mathrm{L} \mathrm{Al}{ }_{2}\left(\mathrm{SO}_{4}\right)_{3}\right)$ by: (4) barite; (5) gypsum; (6) calcite.

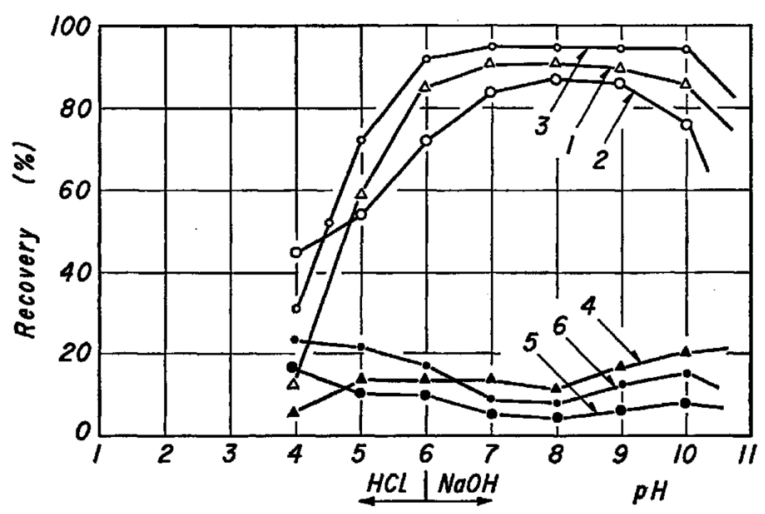

Fig. 6 Recovery of gangue minerals using oleic acid (100 mg/L) as collector: (1) barite; (2) gypsum; (3) calcite; Recovery in the presence of the reagent mixture $\left(50 \mathrm{mg} / \mathrm{L} \mathrm{Na}_{2} \mathrm{SiO}_{3}+50 \mathrm{mg} / \mathrm{L}\right.$ $\left.\mathrm{Al}_{2}\left(\mathrm{SO}_{4}\right)_{3}\right)$ of (4) barite; (5) gypsum; (6) calcite.

showed that it strongly depresses the gangue minerals (Fig. 6) leaving the flotation of the manganese minerals unaffected. The zeta potential data of the barite, the gypsum, and the calcite in the solution of the reagent mixture $\left(50 \mathrm{mg} / 1 \mathrm{Na}_{2} \mathrm{SiO}_{3}+50 \mathrm{mg} / 1 \mathrm{Al}_{2}\left(\mathrm{SO}_{4}\right)_{3}\right)$ are indications to the electrostatic nature of an interaction phenomena. The curves have a similar appearance and show a marked reduction of the zeta potential in the $\mathrm{pH}$ range $5 \sim 9$. The zeta potentials ultimately change their sign indicating the adsorption of an anion.

The available data in the literature ${ }^{(8)(9)}$ suggest that the conjunction of water glass $\left(\mathrm{Na}_{2} \mathrm{SiO}_{3}\right)$ with aluminium sulphate, $\mathrm{Al}_{2}\left(\mathrm{SO}_{4}\right)_{3}$ gives the complex compound $\mathrm{Na}_{2} \mathrm{Al}_{2} \mathrm{SiO}_{3}(\mathrm{OH})_{6}$, which on dissociation gives the anion $\mathrm{Al}_{2} \mathrm{SiO}_{3}(\mathrm{OH})_{6}^{--}$. It seems likely that this hydrophilic anion possesses a tremendous affinity for the positively charged surfaces of the gangue minerals over the negatively charged surfaces of the manganese minerals. The following mechanism seems, therefore,

(8) M. A. Eigels: Bases of flotation of Non-Sulphide minerals, Publ. House "NEDRA", Moscow, (1964), p. $217 \sim 220$ (in Russian).

(9) V. A. Glembtski, V. I. Klassen and I. N. Plaksin: Flotation, Publ. "GOSGORTEKHIZDAT", Moscow, (1961), p. 168 (in Russian). 
probable:

$$
\begin{aligned}
& >\mathrm{CaOH}_{2}^{+}+\mathrm{Al}_{2} \mathrm{SiO}_{3}(\mathrm{OH})_{6}^{--} \\
& \quad=>\mathrm{Ca}_{\mathrm{Al}} \mathrm{SiO}_{3}(\mathrm{OH})_{6}^{-}+\mathrm{H}_{2} \mathrm{O} \quad(\mathrm{pH} 5 \sim 8)
\end{aligned}
$$

Barium sites behave like calcium. This may explain the reverse of the sign of the zeta potentials.

Adsorption and flotation studies (Figs. $7 \sim 9$ ) show that rhodochrosite adsorbs more oleic acid than pyrolusite or manganite, whence it responds much better to soap flotation without preactivation. However, there is a great increase in $\mathrm{OlH}$ adsorption with $50 \mathrm{mg} / \mathrm{L}$ of $\mathrm{CuSO}_{4}$, or $\mathrm{MnSO}_{4}$ addition, at certain and specific for each cation $\mathrm{pH}$ range, by both pyrolusite and manganite. This may be thought to be due to the reduction of columbic repulsion forces by adsorption $\mathrm{Cu}^{++}, \mathrm{CuOH}^{+}, \mathrm{Mn}^{++}$, and $\mathrm{MnOH}^{+}$species onto the negatively charged surface of pyrolusite and

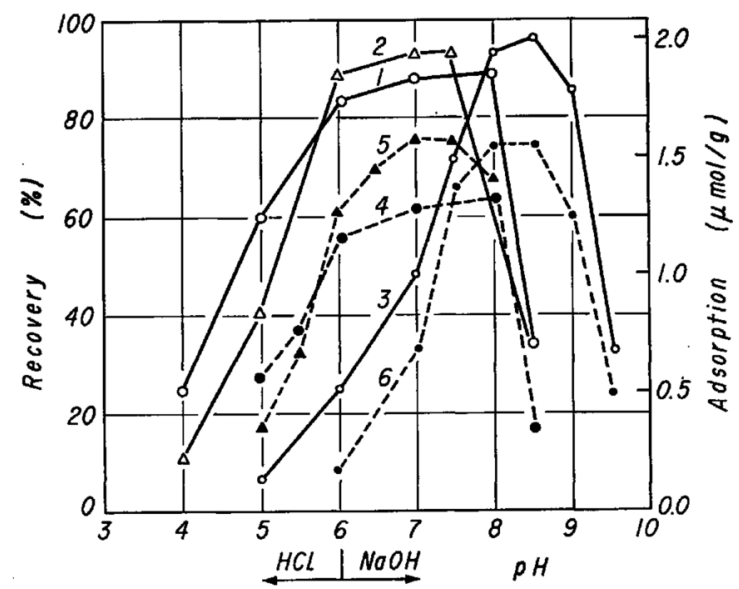

Fig. 7 (The continuous lines represent recovery and the dashed lines represent the adsorption). Recovery of, and the uptake of oleic acid (100 $\mathrm{mg} / \mathrm{L}$ ) from solution by, pyrolusite: $(1 \& 4)$ without preactivation; $(2 \& 5)$ in the case of preactivation with $50 \mathrm{mg} / \mathrm{L} \mathrm{CuSO}_{4} ;(3 \& 6)$ in the case of preactivation with $50 \mathrm{mg} / \mathrm{L} \mathrm{MnSO}_{4}$. N.B: Fe (III) shows almost no activation.

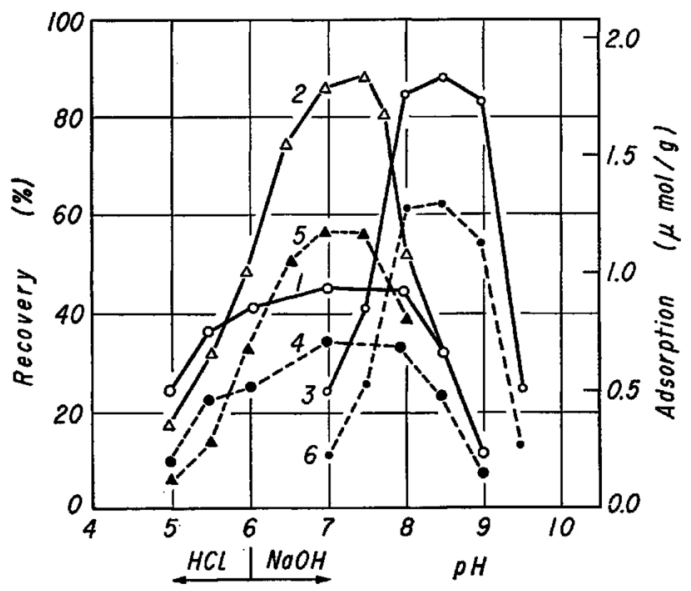

Fig. 8 (The continuous lines represent recovery and the dashed lines represent the adsorption). Recovery of, and the uptake of oleic acid (100 $\mathrm{mg} / \mathrm{L}$ ) from solution by, manganite: $(1 \& 4)$ without pre-activation; $(2 \& 5)$ in the case of pre-activation with $50 \mathrm{mg} / \mathrm{L} \mathrm{CuSO}_{4} ;(3 \& 6)$ in the case of pre-activation with $50 \mathrm{mg} / \mathrm{L} \mathrm{MnSO}_{4}$. N.B: Fe (III) shows almost no activation.

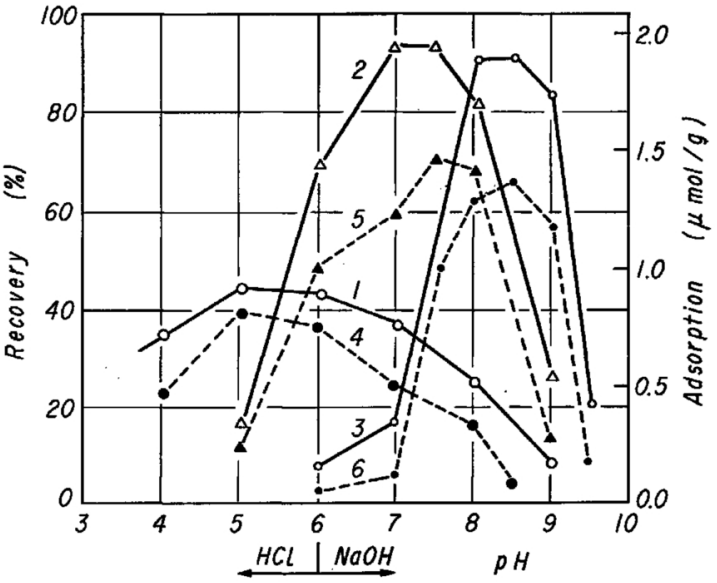

Fig. 9 (The continuous lines represent recovery and the dashed lines represent the adsorption). Recovery of, and the uptake of oleic acid (100 $\mathrm{mg} / \mathrm{L}$ ) from solution by, rhodochrosite: (1 \& 4) without pre-activation; ( $2 \& 5)$ in the case of pre-activation with $50 \mathrm{mg} / \mathrm{L} \mathrm{CuSO}_{4} ;(3 \& 6)$ in the case of pre-activation with $50 \mathrm{mg} / \mathrm{L} \mathrm{MnSO}_{4}$. N.B: Fe (III) shows almost no activation.

manganite rendering their surfaces less negative. In addition, $\mathrm{Cu}(\mathrm{II})$ and $\mathrm{Mn}(\mathrm{II})$ create active sites, suitable for the attachment of collector species. As seen from Figs. 7 and $8 \mathrm{Cu}$ (II) and $\mathrm{Mn}$ (II) are effective activators in the $\mathrm{pH}$ range $6.5 \sim 8$ and $8 \sim 9$, respectively. On the other hand, $\mathrm{Cu}$ (II) and $\mathrm{Mn}$ (II) decrease the adsorptive capacity and floatability of manganese minerals at pHs below 6.5 and 8 , respectively.

An interpretation of these results may be given if we take into consideration the state of $\mathrm{Cu}$ (II) and $\mathrm{Mn}$ (II) (eqs. (1) $\sim(7)$ ) and the state of oleic acid in solution. An infrared spectroscopy study ${ }^{(11)}$ of oleic acid and sodium oleate solutions showed that the $p K_{a}$ of $\mathrm{OlH}$ is about 8. At $\mathrm{pH}$ below $5.2 \mathrm{OlH}$ (undissociated oleic acid molecules) is the only species present in solution. The relative concentrations of $\mathrm{OlH}$ at $\mathrm{pHs} 7$ and 8.5 are 90 and $17 \%$, respectively, while the corresponding values for $\mathrm{Ol}^{-}$species are 10 and $68.2 \%$. On the bases of these data and zeta potential data (eqs. (8) $\sim(11)$ ) the following mechanism may be postulated:

$$
\begin{gathered}
>\mathrm{MnO} . \mathrm{OHMn}+\mathrm{Ol}^{-}=>\underset{\mathrm{MnO} . \mathrm{OHMnOl}^{-}}{(\mathrm{pH} 8 \sim 9)} \\
>\mathrm{MnO} . \mathrm{OHCu}=>\underset{\mathrm{MnO} O \mathrm{OHCuOl}{ }^{-}}{(\mathrm{pH} 7 \sim 8) .}
\end{gathered}
$$

The deactivating action of $\mathrm{Cu}(\mathrm{II})$ and $\mathrm{Mn}$ (II) on the adsorptive capacity and floatability of manganese minerals may be due to the attachment of these cations to $>\mathrm{MnOH}$ sites (eqs. (9) and (11)), whence the attachment of oleic acid to these suitable sites (eq. (19)) become rather improbable.

$$
>\mathrm{MnOH}+\mathrm{HOl}=>\mathrm{MnOH} . \mathrm{HOl} \quad(\mathrm{pH} 3 \sim 5) \text {. }
$$

(10) I. N. Kraos, V. A. Derebiankin and S. I. Kyznutsova: The Soviet J. of Non-Ferr. Metals, (7) (1968), 43 (in Russian).

(11) S. I. Polkin, G. S. Berger and I. B. Ribazachvili: Trans. of the higher Educational Establishments, Non-Ferr. Metallurgy, (3) (1968), 6 (in Russian). 
Figure 9 shows that a rhodochrosite adsorbs without pre-activation with metal cations or sulfur dioxide $\left(\mathrm{SO}_{2}\right)$, oleic acid being in sufficient quantities for flotation to take place. Since the main difference between the manganese surface sites of a rhodochrosite and a pyrolusite is in that in the former the manganese is bivalent and in the latter is quadrivalent, it seems likely that the bivalent manganese site is more suitable, than the quadrivalent manganese site, for the attachment of oleic acid. Indeed, the available data in the literature $^{(12)}$ confirm that $\mathrm{Mn}(\mathrm{II})$ compounds are stable, whereas those of $\mathrm{Mn}(\mathrm{IV})$ are unstable. In addition, the low dissociation constant of both $\mathrm{H}_{2} \mathrm{CO}_{3}$ $\left(10^{-7}\right)$ and $\mathrm{HCO}_{3}^{-}\left(10^{-11}\right)$ promotes the attachment of oleic acid to the carbonate sites. Thus, the mechanism by which oleic acid is attached to the surface of a rhodochrosite is:

$$
\begin{aligned}
& >\mathrm{CO}_{3} \mathrm{H}+\mathrm{Ol}^{-}=>\mathrm{CO}_{3} \mathrm{H}_{2} \mathrm{Ol}^{-} \quad(\mathrm{pH} 6 \sim 10) \\
& >\mathrm{MnO}^{-}+\mathrm{OlH}=>\mathrm{MnO} . \mathrm{HOl} \quad(\mathrm{pH} 6 \sim 8)
\end{aligned}
$$

\section{Conclusions}

The suggestion of some investigators ${ }^{(13)(14)}$ that sulfur dioxide $\left(\mathrm{SO}_{2}\right)$ introduces manganese ions in the

(12) H. Remy (Translated by J. S. Anderson; Ed. by J. Kleinberg), Treatise on inorganic chemistry, Vol. 2-Subgroups of the periodic table and general topics. Elseiver Publishing Company, Amsterdam, London, New York Punceton, (1956), p. $218 \sim 225$.

(13) S. J. McCarroll: Trans. AIME, 199 (1954), 289.

(14) Ellis H. Gates: Trans. AIME, 208 (1957), 1368. pulp solutions which are directly responsible for the activation of the manganese minerals soap flotation is partly incorrect, since a rhodochrosite responds fairly well to soap flotation without pre-activation with metal cations or with sulfur dioxide. It seems likely that the activating action of sulfur dioxide on the manganese minerals is due to the reduction of the quadrivalent manganese, $\mathrm{Mn}(\mathrm{IV})$, atoms in the surface of the crystalline lattice of pyrolusite and manganite to the divalent state. Also, the suggestion that heavy metal such as $\mathrm{Cu}$ (II) and $\mathrm{Fe}$ (III) could act as activators is inconsistent with the experimental evidence of this paper. It is to be noted that the feasibility of activation of a manganese mineral with a heavy metal ion is basically determined by the chemical composition of the mineral and the $\mathrm{pH}$ of its isoelectric point as well as the $\mathrm{pH}$ at which the metal ion begins to hydrolyze and precipitates. If the heavy metal ion begins to hydrolyze and precipitate at $\mathrm{pHs}$ equal or below that of the isoelectric point of the manganese mineral, as in the case of $\mathrm{Fe}$ (III), it can not act as activator and on the contrary may act as depressant due to the adsorption of oleic acid by its positively charged colloidal precipitate.

The complex hydrophilic anion $\mathrm{Al}_{2} \mathrm{SiO}_{3}(\mathrm{OH})_{6}^{--}$, which is formed from the conjunction of water glass $\left(\mathrm{Na}_{2} \mathrm{SiO}_{3}\right)$ with $\mathrm{Al}_{2}\left(\mathrm{SO}_{4}\right)_{3}$ is an effective and selective depressant for the gangue minerals (barite, gypsum, calcite). This anion possesses tremendous affinity for the positively charged surfaces of these gangue minerals over the negatively charged surfaces of the manganese minerals leading to a successful differential flotation. 